\title{
GUBERNAMENTALIDAD Y POLÍTICAS DE EMPLEO: LA CONSTRUCCIÓN DISCURSIVA DEL JOVEN TRABAJADOR EN CHILE ${ }^{1}$.
}

\author{
GUILLERMO RIVERA-AGUILERA ${ }^{2}$
}

\begin{abstract}
RESUMEN
El presente artículo describe cómo las políticas de empleo construyen al joven trabajador en Chile. Para esto se realiza un análisis de discurso que toma como referencia documentos públicos de políticas de empleo juvenil elaboradas entre los años 2008-2015. Los resultados dan cuenta que a partir de los lineamientos del Consejo Asesor para el Trabajo y la Equidad (2008), los énfasis están puestos en una serie de prescripciones normativas centradas en la regulación social del empleo juvenil. Desde la perspectiva de los Estudios de la Gubernamentalidad se discute cómo se gobierna a la 'juventud vulnerable' desde un discurso centrado en el Management, la empleabilidad y la autoestima.
\end{abstract}

Palabras Claves: Gubernamentalidad, Políticas De Empleo, Juventud.

\section{GOVERNAMENTALIDADE E POLÍTICAS DE EMPREGO: A CONSTRUÇÃo DISCURSIVA DO JOVEM TRABALHADOR NO CHILE}

\section{RESUMO}

O presente artigo descreve a maneira na qual as políticas de emprego constroem o jovem trabalhador no Chile. Para isto, é realizada uma análise de discurso que tem como referência documentos públicos de políticas de emprego juvenil elaboradas entre os anos 2008-2015. Os resultados mostram que a partir das orientações do Conselho Assessor para o Trabalho e a Equidade (2008), a ênfase está em uma série de prescrições normativas centradas na regulação social do emprego juvenil. Desde a perspectiva dos Estudos da Governamentalidade é discutido como é governada a "juventude vulnerável” a partir de um discurso centrado na Administração, a empregabilidade e a autoestima.

Palavras-Chave: Governamentalidade, Políticas De Emprego, Juventude.

\section{GOVERNMENTALITY AND EMPLOYMENT POLICIES: THE DISCURSIVE BUILDING OF WORKING YOUTH IN CHILE}

\begin{abstract}
This article aims to describe the way in which the employment policies construct the working youth in Chile. Based on a discourse analysis on public documents of youth employment policies between 2008-2015; the results show that from the guidelines from the Advisory Council for Labour and Equality (2008), the emphasis is placed on a series of normative requirements focused on the social regulation of youth employment. From a

\footnotetext{
${ }^{1}$ Este artículo fue elaborado en el marco de mi pasantía de investigación Doctoral en la School of Management de la Universidad de Leicester, Reino Unido. Me gustaría agradecer a la Dirección de Estudios avanzados de la PUCV, cuyo financiamiento permitió mi estancia en este centro de estudios durante el segundo semestre del 2015.

${ }^{2}$ Doctor (C) en Psicología, Pontificia Universidad Católica de Valparaíso. Correo electrónico: griverov@gmail.com
} 
Governmentality Studies-oriented perspective, it is discussed the way in which the 'vulnerable youth' is ruled from a discourse based on Management, employability and selfesteem.

\section{Keywords: Governmentality, EMPloyment Policies, Youth.}

\section{I.- INTRODUCCIÓN}

"Y si hablamos de equidad en el mundo del empleo, es fundamental que facilitemos la inclusión de más mujeres y jóvenes al mundo del trabajo, que son precisamente los grupos que más dificultades tienen para acceder a oportunidades laborales. Justamente para eso creamos el programa Más Capaz, que entrega capacitación técnica, habilidades transversales e intermediación laboral a mujeres y jóvenes, incluyendo jóvenes en situación de discapacidad. El año pasado partimos con un piloto que entregó formación a casi cuatro mil personas y este año el programa ya se despliega a lo largo de todo el país, esperando incorporar a 50 mil mujeres y 25 mil jóvenes. Al final de mi período habremos capacitado a 300 mil mujeres y 150 mil jóvenes (Mensaje Presidencial, 2015: 9).

Una de las primeras medidas desarrolladas por el segundo gobierno de la presidenta Bachelet $^{3}$, fue poner en marcha un nuevo programa de inserción laboral dirigido a mujeres y jóvenes, en situación de vulnerabilidad social. Basado en un discurso centrado en la equidad, la igualdad de oportunidades, la formación de capital humano, el programa denominado 'Más Capaz' se ha planteado como objetivo aumentar la participación e inclusión al mercado del trabajo de 300 mil mujeres y 150 mil jóvenes.

Este tipo de políticas cuyo fin es promocionar el empleo, se materializan a través de programas con características similares a nivel global (Rivera, 2015 $)$. Los discursos que emergen desde las políticas y programas sociales orientados al trabajo prescriben, desde la retórica de la empleabilidad, la inclusión de un sujeto considerado como carente de oportunidades para integrarse a los mercados del trabajo. Siguiendo a autores como Cherkovskaya, Watt, Tramer y Spoelstra (2013), los programas de empleo han sido elaborados como formas de integración e inclusión social, de jóvenes, inmigrantes, viejos, mujeres, personas con discapacidades. A los sujetos de dichos grupos sociales, las políticas y los programas, les invita desde su autodeterminación a salir de su marginalización. Para esto, el usuario debe ser modelado de acuerdo a las exigencias del mercado laboral competitivo (Vargas-Monroy y Pujal, 2013; Miller y Rose, 2009).

Este artículo toma como referencia los Estudios de la Gubernamentalidad para analizar y reflexionar en torno a los discursos existentes en las políticas y programas de empleo juvenil. Esto desde el interés por responder a cómo las políticas de empleo construyen al joven trabajador en Chile, en el marco de las transformaciones del trabajo y los procesos de neoliberalización ocurridos en el país.

Los discursos que emergen de las políticas de empleo juvenil tienen efectos ideológicos. En el caso chileno, permite entender el trabajo y la producción de un tipo de sujeto productivo desde una forma de gobierno Neoliberal. Tal como señalan Fairclough y Wodak (2000), el hecho de centrar el análisis en la ideología y los discursos que ésta

\footnotetext{
${ }^{3}$ Michel Bachelet es la actual presidenta de Chile, asumió su segundo gobierno en marzo del 2014. Su primer gobierno fue entre los años 2006 al 2010.

${ }^{4}$ El artículo mencionado hace referencia a países como Suecia, Argentina, Holanda y Australia.
} 
genera, permite entender y desentramar cómo se producen y reproducen relaciones de poder desiguales entre clases sociales y género, desde la forma en que se sitúa a los sujetos.

En este estudio, entenderemos que programas como 'Más Capaz' intervienen y administran la problemática del empleo-desempleo, orientadas a una población específica de jóvenes. Los llamados ‘jóvenes vulnerables', son interpelados por las políticas sociales y laborales a transformarse en jóvenes productivos, desde una retórica argumentativa basada en un discurso Managerial (Parker, 2002; Sisto, 2012).

Este tipo de políticas de empleo juvenil se sitúa en un contexto internacional y tienen como referencia lineamientos de instituciones como el Banco Mundial y la Organización Internacional del Trabajo (Rivera, 2015). En esta línea, autores como Kaasch (2013) hablan de 'políticas sociales globales', las cuales promueven una serie de conceptualizaciones, normas, orientaciones y métodos para ser aplicados a niveles locales.

Este artículo se sitúa en la realidad chilena y argumenta que el discurso basado en el Management tiene sus orígenes en el "Nuevo enfoque para la equidad" desarrollado por el Consejo Asesor Presidencial: Trabajo y Equidad (CAPTE, 2008: 20) en el año 2008. Estas nuevas políticas, basadas y justificadas en una ideología Neoliberal, se caracterizan por distanciarse de "las 'viejas' políticas sociales" (21), centradas en la superación de necesidades básicas. Desde un argumento basado en la productividad, el crecimiento económico y la competitividad del país, estos lineamientos han repercutido en materia juvenil. A partir de ahora, los énfasis están puestos en una serie de prescripciones normativas centradas en la empleabilidad, la formalidad del trabajo y la autoestima.

\section{Programas de empleo juvenil en Chile}

La elaboración de programas como Más Capaz en Chile no es algo nuevo. Desde el inicio de los 90's y con la llegada de la democracia al país, los primeros gobiernos de la coalición democrática comenzaron a desarrollar programas orientados a la inclusión laboral de jóvenes a los mercados del trabajo. Por aquel entonces las políticas centradas en la población juvenil hablaban de una 'deuda social con la juventud ${ }^{6}$ ' (Aguilera, 2009).

El año 1991 se crea el 'Instituto Nacional de la Juventud' (INJUV) y en materia de empleabilidad para jóvenes se pone en marcha el programa 'Chilejoven' (1991-1998). Este último se posiciona como emblema de política pública en materia de inserción laboral para jóvenes, no sólo para Chile sino también se transforma en un ejemplo para otros países de la Región (Ibáñez, 2005).

Estas formas de entender la inclusión de jóvenes de estratos bajos en el mercado del trabajo se plantean como una de tantas estrategias para disminuir la pobreza y mejorar los índices de empleabilidad del país. A fines de los años 90’s y durante la década del 2000’s aparecen nuevos programas como 'Interjoven', 'Chile Califica' y 'Jóvenes Bicentenario'. Estos programas de características similares a 'Chilejoven', se van ejecutando desde lineamientos ministeriales como una forma de posta programática por los distintos gobiernos de turno.

\footnotetext{
${ }^{5}$ Este nuevo enfoque para la equidad en Chile se ha descrito en el informe: "Hacia un Chile más justo: Trabajo, salario, competitividad y equidad social" (CAPTE, 2008).

${ }^{6}$ Aguilera (2009), tomando como referencia a Rodríguez (2000), sostiene que la situación económica y política existente durante la dictadura militar generó una severa exclusión socioeconómica en jóvenes de sectores populares urbanos.
} 
A mediados de la década del 2000, se desarrolla una importante reflexión y discusión pública en torno a la inequidad existente en materias laborales en Chile. A partir de entonces, el tema principal de la política social deja de ser cómo disminuir la pobreza, sino que la discusión tiene un giro que se centra en cómo enfrentar la inequidad que ha venido aumentando en el país.

Con el fin de hacer frente a esta situación y desde el interés de construir respuestas a nivel país que incluyan a diversos actores sociales, es que, durante el primer gobierno de Bachelet, se crea y se implementa el 'Consejo Asesor Trabajo y Equidad' (CAPTE). Este estamento público-privado es presidido por Patricio Meller $^{8}$ y representado por distintos actores pertenecientes al Estado, la Iglesia, la Sociedad Civil y el sector Empresarial.

En el informe desarrollado por el CAPTE $^{9}$ (2008) se plantea la necesidad de diseñar una nueva y 'mejor política' para el futuro, en el marco del Bicentenario del país. La denominada 'política social y laboral para un nuevo siglo' (23) tiene como eje principal la productividad basada en un discurso centrado en el crecimiento económico, la reconversión laboral y una reactualización permanente de toda fuerza de trabajo (CAPTE, 2008).

Como resultado de las propuestas desarrolladas por el CAPTE, es que durante el año 2008 el Gobierno manda un proyecto de Ley al Congreso Nacional denominado 'Ley Subsidio al empleo Juvenil ${ }^{10}$, (LSEJ), el cual se basa en la necesidad de focalizar un subsidio de empleo centrado en la capacitación para los jóvenes más vulnerables del país. A partir de esta Ley se plantea la necesidad de formalizar el trabajo de los jóvenes chilenos, con el fin de aumentar el capital humano para un mayor crecimiento económico. De esta manera se promueve que la 'juventud vulnerable' se inserte al mercado del trabajo como un sujeto productivo. Esto con el objetivo de que el joven "fortalezca sus lazos de pertenencia con la sociedad y disponga de los recursos y tenga acceso a la protección social necesaria para desarrollar una vida con más y mejores oportunidades" (Congreso Nacional, 2009: 5).

Durante el año 2009, en un contexto de crisis económica mundial, se aprueba la LSEJ, como un paso a la construcción de una política del trabajo más equitativa en materia de juventud e inclusión social. El proceso de tramitación de esta Ley unió a los distintos sectores políticos, desde la importancia de subsidiar por un lado, a la juventud para ser capacitada, así como a las empresas que contratan a los jóvenes. Bajo una serie de discursos de unidad nacional centrados en la juventud, Chile se plantea como ejemplo para sus pares, ya que elabora una serie de medidas en un contexto de crisis económica mundial y se posiciona dentro de las normativas y parámetros que han planteado los organismos internacionales del trabajo. Es durante el año 2009 y producto de esta nueva LSEJ que se invierten 100 millones de dólares, como un financiamiento compartido, para la capacitación dirigida a los jóvenes, así como para las empresas que contratan a los jóvenes trabajadores.

Las 'políticas sociales y laborales para un nuevo siglo', han tenido importantes repercusiones en las nuevas formas de entender el trabajo y las políticas de empleo en Chile. Como se ha señalado, no sólo han justificado inversión pública en materia de subsidios para la población juvenil en materia de empleabilidad, sino también han podido

\footnotetext{
${ }^{7}$ Esta iniciativa se argumenta desde un llamado 'aporte ético' para un Chile más justo.

${ }^{8}$ Patricio Meller es Dr. en Economía de la Universidad de California, Berkeley. En su trayectoria ha sido director ejecutivo de CIEPLAN, consultor del BID, OECD, Banco Mundial y CEPAL. Bachelet eligió a Meller, ya que se trata "de un gran académico y un gran demócrata" que resume el espíritu de la iniciativa (CAPTE, 2008).

9 "Hacia un Chile más justo: Trabajo, salario, competitividad y equidad social".

${ }^{10}$ Ley $\mathrm{N}^{\circ} 20.338$.
} 
prescribir nuevas formas de entender al joven trabajador en Chile, las cuales han sido incorporadas en los últimos años, tanto por los gobiernos de centro derecha de Sebastián Piñera (2010-2014) y de centro izquierda de Michelle Bachelet (2006-2010/ 2014 a la fecha).

Estas nuevas formas de entender al joven trabajador en Chile tienen efectos en cuanto generan una serie de políticas, programas y elementos normativos focalizados en una población específica de los jóvenes. Por ello, este estudio analiza las políticas desde una perspectiva que reflexiona sobre las formas de gobierno de la juventud, para esto la pregunta estará centrada en el 'cómo se gobierna' (Dean, 1995). En esta línea, considerando que en las últimas décadas se ha desarrollado un campo de creciente fuerza en las Ciencias Sociales, que se ha denominado 'Estudios de la Gubernamentalidad', este artículo se basará en esta perspectiva para entender cómo las políticas de empleo juvenil 'conducen la conducta' de los jóvenes vulnerables.

A continuación, presentaremos el enfoque de los Estudios de la Gubernamentalidad y su contribución a los Estudios del Trabajo. También se dialogará con conceptos tales como: Neoliberalismo, Management y Empleabilidad, los cuales permitirán ampliar la mirada del fenómeno de estudio.

\section{Estudios de la Gubernamentalidad y el trabajo}

Como bien se ha descrito en una serie de publicaciones, los 'Estudios de la Gubernamentalidad' tienen sus orígenes en las ideas sobre el poder y las formas de gobierno de las poblaciones desarrolladas por Michel Foucault en los cursos "Seguridad Territorio y Población” (1978) y "El Nacimiento de la Biopolítica” (1979), impartidos en el Collège de France (Burchell, Gordon, Miller, 1991; Castro-Gómez, 2010; Flew, 2014; Grinberg, 2007; Miller y Rose, 2009; Rose, O’Malley, Valverde, 2012; Sennelat, 2009; Vargas-Monroy y Pujal, 2013).

Desde los Estudios de la Gubernamentalidad se desprende un desarrollo en la literatura de las ciencias sociales y en la teoría política. Siguiendo a Mitchel Dean (2007), el trabajo producido en las últimas décadas puede ser visto como si formara una nueva subdisciplina de las ciencias sociales y humanas, preocupada por la forma en que el gobierno es llevado a cabo, por el 'cómo' del gobierno. En esta línea, Rose, O’Malley, Valverde (2006) afirman que el enfoque sobresale por "su insistencia en entender cómo somos gobernados en el presente individual y colectivamente, en nuestros hogares, escuelas, hospitales, ciudades, regiones y naciones, tanto por parte de nuestros cuerpos de gobierno nacionales así también por parte de los transnacionales" (Rose et al., 2006: 143).

La pregunta está centrada en el cómo se gobierna y no en el qué se gobierna. Tal como sostiene Dean (1995), estos estudios se centran en el cómo se conduce la conducta de los sujetos como forma de gobierno de las poblaciones. Estas formas de entendimiento han permitido "iluminar aspectos de nuestra vida social y política, particularmente aquella que concierne el sentido de conducta de la conducta, particularmente, la relación entre gobierno y conducta" (560).

Siguiendo las ideas de Foucault sobre la Gubernamentalidad, entenderemos que las políticas de empleo juvenil se desarrollan desde una racionalidad centrada en 'conducir la conducta' de los jóvenes. Esto con la finalidad de hacer que ejerzan su libertad de modos específicos, basados en los objetivos estratégicos de programas de empleo y del mercado del trabajo (Castro Gómez, 2010; Du Gay, 1996; Stecher y Godoy, 2014). 
Si bien los estudios de Gubernamentalidad fueron inicialmente cuestionados por su poca aplicación empírica y por tener características eurocéntricas, en los últimos años se han desarrollado una serie de investigaciones sobre el trabajo y el empleo desde este enfoque (Rose, 2006; Grinberg, 2007; Vargas-Monroy y Pujal, 2013; Mussetta, 2009). Estos estudios empíricos se desarrollan principalmente desde el mundo anglosajón (Cherkovskaya et al., 2013; Miller y Rose, 2009), escandinavo (Diedrich y Styhre, 2013; Fejes, 2010; Garsten y Jacobsson, 2013; Vesterber, 2013; Holmqvist, Maravlias, Skalen, 2012) y existe una corriente emergente desde Latinoamérica (Assusa y Brándam, 2014; Brándam, 2014; Castro-Gómez, 2010; Pulido-Martínez, 2012, 2008; Sáenz y Granada, 2013; Vargas-Monroy y Pujal, 2013).

\section{La ideología neoliberal y el Management}

Siguiendo con las ideas de Foucault, desarrolladas en el curso "El Nacimiento de la Biopolítica" de 1979, entenderemos el Neoliberalismo como una 'tecnología de gobierno' y un 'arte de gobernar'. Sus orígenes obedecen a una racionalidad proveniente del liberalismo (Foucault, 1979/2012; Flew, 2014; Castro-Gómez, 2010; Miller y Rose, 2009).

Para este estudio, siguiendo las ideas de Tadajewsky, Maclaran, Parson, Parker (2011), entenderemos el Neoliberalismo" como "una ideología y una práctica política. Sostiene que el bienestar y los bienes sociales serían maximizados si el mercado se extiende desde la noción de propiedad a cada esfera de la interacción humana" (Tadajewsky et al. 2011: 173).

Esta ideología y práctica política de orden Neoliberal se materializa en una serie de discursos que prescriben las formas de entender los modos de producción y del trabajo en nuestras sociedades actuales. Es más, tal como señalan Rose (1996), Du Gay (1996), Parker, Cheney, Fournier, Land (2014), la ideología repercute también en las subjetividades, ya que construye un tipo de ser humano: un sujeto libre, un homo economicus, un trabajador flexible. Estas figuras de subjetividad son centrales en la ideología neoliberal y en las formas de gobernar a la población juvenil desde lineamientos globales (Parker et al., 2014; Rivera, 2015).

En esta línea, recientemente Hanlon (2016) plantea la idea del Management como la primera ciencia neoliberal basándose en argumentos morales y políticos. Sostiene que el discurso centrado en la objetividad basada en la eficiencia del Management, han generado nuevas formas de autoridad y de poder, contribuyendo así a una serie de intereses políticos. Desde estos argumentos, Hanlon afirma que se ha manipulado la ética del trabajo, legitimando al Management para administrar el espacio del trabajo y también a la sociedad en su conjunto.

De acuerdo a la perspectiva de los Critical Management Studies $(\mathrm{CMS})^{12}$, más que ser natural, científico y objetivo, el Management puede entenderse como un sello

\footnotetext{
${ }^{11}$ Autores como Flew (2014) han señalado que es mucho lo que se ha escrito sobre neoliberalismo en los últimos años y advierten que las definiciones de este concepto varían enormemente desde distintas disciplinas y perspectivas. En sus propias palabras, el Neoliberalismo es un "concepto muy invocado pero muy mal definido" (Flew, 2014: 53). Sin embargo, la definición propuesta en este estudio identifica elementos claves que definen las políticas de empleo juvenil.

${ }^{12}$ Los Critical Management Studies (CMS), se traducen como los Estudios Críticos de la Administración. Son una disciplina que se propone analizar las empresas y las organizaciones desde una perspectiva crítica. Se pueden entender como la aplicación de la teoría crítica y del marco teórico postmoderno a los estudios sobre la gestión empresarial, distanciándose del discurso mainstream (Fernández-Rodríguez, 2012; Alvesson, 2008). Para introducirse a su desarrollo en Chile revisar Espinoza y Rivera (2015).
} 
característico de las políticas y de la ideología neoliberal (Hanlon, 2016; Parker, 2002). Según Parker (2002), la concepción dominante en nuestras sociedades actuales es la aplicación de formas de Management que operan como tecnologías de control. Esto ocurre desde al menos dos formas. En primer lugar, desde la aplicación de un lenguaje o un discurso managerial a áreas cada vez más informales de la vida. Y en segundo lugar, entendiendo el Management como disciplina intelectual y práctica que es capaz de responder a las demandas del mercado. Siguiendo estas ideas podemos entender el Management como un saber que es aplicado a una serie de dominios y obedece a una forma de pensamiento que es usada para justificar la inequidad (Parker, 2002). A continuación, se presentan los conceptos de empleabilidad y capital humano, para entender como esta ideología neoliberal se materializa en las formas de entender el trabajo y al trabajador en las sociedades contemporáneas.

\section{El concepto de empleabilidad y capital humano en un contexto neoliberal}

En las últimas décadas, las nociones de la empleabilidad y el capital humano han sido relevantes en los discursos del trabajo en Chile. Tal como se ha documentado, en las sociedades Neoliberales el Estado ya no es responsable de proveer un trabajo duradero y seguro (Cherkovskaya, 2013; Garsten y Jacobsson, 2013). La tendencia de los mercados laborales es centrar su atención en la competencia, la movilidad, la flexibilidad y el aprendizaje continuo. En este escenario, podemos entender la empleabilidad como una exigencia para las personas (Renteria y Malvezzi, 2008), donde la capacidad individual del sujeto para tomar iniciativas, la forma de actualizar conocimientos y desarrollar habilidades, corresponden a orientaciones claves para el sujeto que busca empleo (Cherkovskaya et al., 2013; Garsten y Jacobsson, 2013; Pulido y Sato, 2013; Miller y Rose, 2009; Rose 1996). En esta línea, Renteria y Malvezzi (2008), basados en las ideas de Gazier (2001), argumentan que las exigencias puestas en los sujetos obedecen a formas idealizadas de individuos competentes, que se manifiestan en perfiles que se construyen desde discursos institucionalizados que son legitimados por las políticas públicas. Estas últimas son las que finalmente definen quién será o no será empleable.

El 'Individuo empleable', es una categoría normativa en los discursos actuales del mercado del trabajo. Hace referencia a lo que es necesario para ser atractivo en un mercado cambiante (Fejes, 2010). La experiencia laboral ya no es suficiente, las habilidades blandas, flexibilidad y adaptabilidad son requeridas, así como la capacidad de venderse a uno mismo (Garsten y Jacobsson, 2013).

Esta forma de entender la empleabilidad se conecta con la Teoría del Capital Humano (Becker, 1993; Shultz, 1971), la cual ya durante la década de los 1970's fue fuertemente cuestionada por autores posestructuralistas (Foucault, 1979/2012) y neomarxistas (Bowles y Gintis, 1975/2014), desde el argumento que descompone la categoría de trabajo en un capital y en una renta, teniendo como consecuencia que entendamos al trabajador como empresa de sí-mismo. Proporcionando, de esta forma, los lineamientos para una ideología que defiende el status quo, puesto que atribuye los 
problemas sociales o individuales a fallas de los individuos y no a temas estructurales del sistema $^{13}$ (Bowles y Gintis, 2014).

En términos de la empleabilidad, la Teoría de Capital Humano plantea la escolarización y la capacitación como parte integral de una mano de obra disciplinada que está relacionada directamente con las relaciones sociales de producción (Bowles y Gintis, 1975). En esta línea, algunos autores de la literatura anglosajona y escandinava han señalado que la noción del empleo resta importancia a elementos estructurales del mercado del trabajo, el acceso y las inequidades, e individualiza los problemas sociales (Holmqvist, 2009; Chertkovskaya et al., 2013). Por otro lado, Renteria y Malvezzi (2008) cuestionan el concepto de empleabilidad, ya que no puede ser reemplazado por las formas de entender el trabajo. Sostienen que reducir la crisis de las organizaciones y del trabajo a las competencias del trabajador es no querer enfrentar la problemática existente.

En relación a los conceptos y a las perspectivas teóricas presentadas, esta investigación entiende las políticas públicas orientadas al empleo juvenil como el resultado de un accionar de las instituciones, que interpelan al joven como trabajador y que en determinado momento prescriben formas de diagnosticar e intervenir a la juventud. Tal como ha señalado Fejes (2010), estos criterios pueden ser analizados desde documentos oficiales de uso público. Para esto se desarrolla un análisis documental (Atkinson y Coffey, 2006; Prior, 2006) tomando como referencia los informes, leyes y documentos programáticos asociados a las políticas de empleo y juventud en Chile desde el año 2008 a la fecha. Considerando lo anterior, este estudio busca entender cómo las políticas de empleo despliegan un discurso que generan un engranaje para entender cómo se construye el joven trabajador en Chile. Lo que se presenta a continuación es el resultado del análisis documental mencionado.

\section{II.- MÉTODO}

Para ilustrar como se construyen los discursos sobre el joven trabajador en las políticas de empleo en Chile, se realizó un Análisis Crítico del Discurso (Parker, 1996; Fairclough, 2010; Fairclough y Wodak, 2000; Jäger, 2000; Stecher, 2010, 2014), que toma como referencia la técnica el Análisis Documental (Atkinson y Coffey 2006; Prior, 2006).

Para este estudio, el discurso es entendido como una práctica social. En palabras de Fairclough y Wodak (2000) "el hecho de describir el discurso como práctica social sugiere una relación dialéctica entre un suceso discursivo particular y las situaciones, instituciones y estructuras sociales que la enmarcan" (367). Desde esta perspectiva, se centrará el análisis en los discursos respecto a cómo el joven trabajador es pensado, gestionado y gobernado.

Estos discursos que construyen al joven trabajador chileno pueden dilucidarse desde documentos que realiza la política pública sobre empleabilidad juvenil. Algunos ejemplos de este tipo de discurso son los debates parlamentarios, los documentos de prensa, informes oficiales en materia de procesos gubernamentales y discursos de expertos, que se basan en investigaciones y datos empíricos en relación a la problemática (Sisto y Fardella, 2011). En esta línea, nos interesa profundizar la justificación de la política, es decir, qué discursos justifican y difunden los diseños de políticas y sus dispositivos (Kurunmäki, Lapsley y Miller, 2011).

\footnotetext{
${ }^{13}$ De acuerdo a Browles y Gintis (1975), la perspectiva marxista la Teoría del Capital Humano elimina el concepto de clase como elemento central. A partir de esa presunción, todos los trabajadores se transforman en sujetos capitalistas.
} 
Siguiendo a Atkinson y Coffey (2006), entenderemos los documentos como actores, es decir, como objetos que desarrollan cosas. Legitiman la autoridad y validan formas de poder. En este sentido, la relevancia del análisis de documentos radica en que los textos, sean documentos oficiales y/o discursos de autoridades, sirven para: presentar una lógica de gestión, actuar en el terreno local, interpelar a los actores, moldear relaciones, prescribir acciones, estandarizar y categorizar a los sujetos. Así, para esta investigación la clave del papel de los documentos es que estandarizan y categorizan la población juvenil.

Sisto y Fardella (2011) sostienen que el análisis documental permite comprender cómo a través de los textos, se despliegan estrategias retóricas las cuales construyen ciertas versiones de lo real. Ese análisis no sólo debe inspeccionar los documentos en sí mismos, sino la forma en que son producidos, circulados, leídos y usados para una amplia variedad de propósitos (Atkinson y Coffey, 2006).

Para este estudio se seleccionó como corpus 12 documentos públicos sobre políticas de empleo juvenil en Chile. Estos incluyen Informes de comisiones de expertos, proyectos de Ley, encuestas de juventud y mensajes presidenciales desarrollados entre los años 2008 y 2015.

\section{Tabla $N^{\circ} 1$ : Documentos seleccionados para este estudio}

- Consejo Asesor Presidencial (2008): Informe Trabajo y Equidad: "Hacia un Chile más justo: Trabajo, salario, competitividad y equidad social".

- Gobierno de Chile (2009): Mensaje de S.E la Presidenta de la República con que inicia un proyecto de ley que crea el subsidio al empleo.

- Cámara de Diputados (2009): Discusión en sala Subsidio al empleo juvenil. Primer trámite constitucional. Legislatura 357, Sesión 02. Fecha 12 de marzo, 2009.

- Senado de la República (2009): Informe de la comisión de Hacienda recaído en el proyecto de ley en segundo trámite constitucional, que crea el subsidio al empleo. 18 de marzo, 2009.

- Senado de la República (2009): Discusión en sala "Subsidio al empleo juvenil". Legislatura 357, Sesión 04. Fecha 18 de marzo, 2009.

- Congreso Nacional (2009): Oficio de Ley a S.E. la Presidenta de la República, comunica texto aprobado por el Congreso Nacional. Fecha 19 de marzo, 2009.

- Ministerio del Trabajo y previsión Social (2009): Ley N²0.338 Crea el subsidio al empleo. Publicación Diario Oficial. $1^{\circ}$ de abril, 2009.

- Gobierno de Chile (2009): Firma proyecto de Ley Subsidio al empleo. Intervención de S.E la Presidenta de la República Michelle Bachelet, en acto de firma del proyecto de ley sobre subsidio al empleo.

- Instituto Nacional de la Juventud (2013). Séptima Encuesta Nacional de Juventud.

- Gobierno de Chile (2014): Mensaje Presidencial 21 de mayo 2014.

- Servicio Nacional de Capacitación y empleo (2015). Guías operativas 2015. Programa Más Capaz.

- Gobierno de Chile (2015): Mensaje Presidencial 21 de mayo 2015.

De acuerdo a Sisto y Fardella (2011), este tipo de documento público resulta fuente de gran riqueza para mostrar el funcionamiento de la retórica justificativa con la cual se 
instalan transformaciones en política pública, ya que interpelan las identidades de los actores sociales involucrados.

Del corpus analizado, se seleccionaron inicialmente 25 citas que daban cuenta de cómo se construye discursivamente al joven trabajador en Chile. Estás fueron ordenadas en cuatro categorías: 'la mejor política social', 'la focalización de los jóvenes más vulnerables', la formalización del trabajo y 'el joven analfabeto del Management'.

Los resultados se presentan desde dos ejes. El primero 'descriptivo-secuencial', que se ha denominado 'La regulación social del empleo juvenil en Chile', da cuenta de cómo se van desarrollando una serie de transformaciones en las políticas del trabajo en Chile, teniendo como repercusión una serie de variaciones discursivas en torno al joven trabajador desde el año 2008 a la fecha. Para ejemplificar este proceso secuencial de construcción discursiva de la juventud se presentan cuatro citas del corpus seleccionado ordenadas de acuerdo a las categorías mencionadas.

El segundo eje 'analítico' se ha denominado 'de la ideología al sujeto: Neoliberalismo y la producción del joven trabajador chileno'. Este se centra en dos temas que constituyen los hilos discursivos (Fairclough, 2010) que responden a la pregunta de investigación: 'Las políticas Neoliberales centradas en la autoestima' y 'la obsesión por la formalidad del trabajo'. Finalmente, se desarrollará una discusión de cómo los resultados presentados contribuyen a entender el engranaje discursivo que construye al joven trabajador en Chile.

\section{III.- RESULTADOS}

\section{Eje 1.- La Regulación Social del empleo juvenil en Chile}

\section{Categoría 1: La mejor política social}

\section{Cita $n^{\circ} 1$}

'Política Social y Laboral para un Nuevo siglo' (Subtitulo)

(...) La "mejor política social" consiste en que cada persona tenga un empleo, y que éste proporcione un ingreso que permita cubrir un nivel de vida satisfactorio. En consecuencia, el nuevo principio básico de las políticas sociales no radicaría en aliviar la situación aflictiva de los que están fuera del mercado del trabajo para que permanezcan al margen. El propósito central es inducir e incentivar a las personas a capacitarse, buscar empleo y trabajar. Este nuevo foco sustituye los problemas de dependencia y asistencialismo de las políticas sociales del siglo $X X$, poniendo los acentos en la autoestima y la autosustentación.

(Informe Trabajo y Equidad: "Hacia un Chile más justo: Trabajo, salario, competitividad y equidad social”. CAPTE, 2008.p.23)

El fragmento seleccionado, es parte del Informe "Hacia un Chile más justo: Trabajo, salario, competitividad y equidad social" del año 2008. En este documento se define una 'Política social y laboral para un Nuevo siglo', la cual está centrada en una nueva forma de entender el trabajo y las políticas sociales en Chile de cara al siglo XXI. A partir de esta nueva retórica se promueve una población económicamente activa, donde 'cada persona 
tenga un empleo, y que éste proporcione un ingreso'. De esta perspectiva, los chilenos y chilenas deben asumir un rol de sujetos productivos para acceder a un capital económico y por lo tanto lograr 'un nivel de vida satisfactorio'.

En la cita presentada podemos dar cuenta de un discurso que hace referencia a una temporalidad de carácter dicotómico en la política, que se argumenta en un antes y un después, existiendo una relación comparativa entre una nueva política y una antigua política. La mejor política es la política que se plantea para el futuro, la cual está centrada en un ciudadano activo, que es productivo y funcional al mercado del trabajo, marcando una distancia con las antiguas políticas asistenciales propias del siglo XX. A partir de lo anterior, vemos cómo la construcción centrada en una 'mejor política' genera una oscilación discursiva (Fairclough, 2010) en las demandas normativas en relación al trabajo.

En las propuestas desarrolladas por el informe del CAPTE (2008), emerge un discurso directo e imperativo basado en la premisa que la población que esta fuera del mercado del trabajo (o 'al margen'), debe ser 'inducida' al mercado, es decir, debe 'capacitarse, buscar empleo y trabajar'.

La retórica normativa centrada en imperativos como 'inducir', da cuenta de cómo, a partir de un saber centrado en el cuerpo, se van desarrollando formas de subjetivación de la población. En esta línea, el discurso emergente de la 'mejor política' facilitará la comprensión de una serie de tecnologías de gobierno (Castro Gómez, 2010) que permiten formas de 'administración de la subjetividad' (Rose, 1996), centradas en el sujeto y su autoestima basadas en la perspectiva del autogobierno. En esta línea y siguiendo a Cruikshank (1993), las políticas centradas en la autoestima obedecen a una perspectiva centrada en disminuir los sujetos problemáticos carenciados y asistidos. Afirmaciones tales como 'poniendo los acentos en la autoestima y la autosustentación', dan cuenta de la forma en que la perspectiva del autogobierno se plasma en las 'políticas sociales y laborales para el nuevo siglo'. Esto último, desde una perspectiva de la Gubernamentalidad, puede ser entendido como una tecnología de gobierno, centrada en el empleo y la productividad. Esta idea será desarrollada más adelante en el eje analítico.

En la siguiente cita vemos como estas trasformaciones del trabajo en Chile repercuten directamente en las políticas de empleo juvenil. Para esto hemos seleccionado un fragmento de la 'Ley Subsidio al empleo Juvenil' del año 2009, la cual se basa en la necesidad de focalizar un subsidio de empleo centrado en la capacitación para los jóvenes más vulnerables del país. A partir de esta Ley se plantea la necesidad de formalizar el trabajo de los jóvenes chilenos desde la perspectiva del capital humano para un mayor crecimiento económico. De esta manera se promueve que la 'juventud vulnerable' se inserte al mercado del trabajo con la finalidad de que contribuya al crecimiento económico del país como un sujeto productivo.

\section{Categoría 2: Focalización en los jóvenes más vulnerables}

\section{Cita $N^{\circ} 2$}

'La necesidad de focalizar el subsidio en los jóvenes más vulnerables' (Subtítulo). Existen más de 768.000 chilenas y chilenos que son jóvenes entre 18 y 24 años que pertenecen a los sectores más vulnerables de nuestro país. Ellos conforman un sector de nuestra sociedad que enfrenta enormes dificultades ante el desafío de trabajar. La tasa de participación laboral de los jóvenes del quintil más pobre del país es un 60 por 
ciento inferior a la del quintil más rico. Los jóvenes carecen de experiencia laboral y muchos de ellos también carecen de habilidades certificadas, lo que perjudica sus potencialidades de productividad. Esta realidad es especialmente preocupante en los hogares más vulnerables, donde las habilidades productivas de los diferentes oficios aún son transmitidas a los jóvenes por sus padres o por sus familiares directos o tutores, que a su vez también han tenido trabajos informales, de forma tal que se reproduce el círculo de la informalidad y la precariedad social. Además, los jóvenes más vulnerables tienen serias dificultades para encontrar trabajo, ya que carecen de redes laborales. Por otra parte, un porcentaje importante de los jóvenes carecen de los hábitos y de la disciplina necesaria para mantener y progresar en un trabajo subordinado, a lo cual se suma la falta de apoyo de la sociedad para ayudar a definir el tipo de trabajo que se acomoda más a sus expectativas y preferencias. Por último, es inevitable consignar que los primeros salarios que reciben los jóvenes que pertenecen a los hogares más vulnerables son sustancialmente menores que los que reciben los jóvenes de familias de mayores ingresos, lo que en muchos casos desincentiva la búsqueda de un trabajo formal o la permanencia en el mismo. Estas dificultades generan los incentivos para la búsqueda de otras fuentes de ingresos, tanto en el sector informal o en otras actividades que pueden llevar al joven incluso a la delincuencia, con las graves consecuencias personales, familiares y sociales que esto acarrea. Estos factores inciden en que este grupo de la población se demore más tiempo en encontrar un empleo, e incide en que muchos jóvenes se vean tempranamente desalentados en sus intentos de encontrar empleo. Todas estas dificultades de acceso han provocado una persistente baja en la participación laboral de los jóvenes, con la consecuente exclusión productiva y social, además de una alta rotación laboral.

(Mensaje de la Presidenta para iniciar proyecto de ley que crea el subsidio al empleo. Congreso Nacional, 2009: 5).

La segunda cita es tomada desde el mensaje enviado por la Presidenta a la cámara de diputados, con el cual se argumenta el inicio de un proyecto de ley para la creación del Subsidio al Empleo juvenil. El fragmento seleccionado, permite ilustrar cómo en base a un discurso centrado en la carencia, la familia de origen, la informalidad, la inequidad y la delincuencia, se va caracterizando un tipo de joven que se hace necesario focalizar como una población específica en relación al trabajo: 'los jóvenes más vulnerables'.

Éstos se caracterizan por ser 'jóvenes carentes', ya que no tienen experiencia laboral, no poseen habilidades sociales para el empleo, ni redes sociales necesarias para insertarse al mercado laboral. Este joven vulnerable se asocia a un trabajador informal, sus 'habilidades productivas' son transmitidas desde la familia de origen. Desde este argumento, podemos entender que la familia obedece al actor responsable de la informalidad del trabajo de estos jóvenes, hecho que explica la reproducción de un 'círculo de la informalidad y precariedad social', que se hace necesario erradicar desde los lineamientos de las nuevas políticas de empleo.

A partir de lo anterior, vemos cómo emerge un discurso managerial (Parker, 2002) basado en el argumento que los 'jóvenes carecen de los hábitos y de la disciplina necesaria para mantener y progresar en un trabajo subordinado'. Este tipo de afirmaciones se hacen relevantes para comprender la forma en que se está prescribiendo la inclusión laboral del joven trabajador chileno. Aquí el discurso empresarial se hace presente en el diagnóstico de 
la política, emitiendo una normativa hacia el joven que busca empleo desde dos características explicitas. En primer lugar, el joven trabajador debe tener 'la disciplina necesaria', asociada a una serie de habilidades blandas, que de acuerdo a Ibáñez (2005) no son transmitidas en la educación formal ni tampoco por las familias de origen. En segundo lugar, el joven vulnerable como usuario del subsidio, está caracterizado para transformarse en un trabajador subordinado.

Por otro lado, en el fragmento emerge un discurso centrado en la inequidad que plantea algunas contradicciones existentes en la realidad chilena. Esto se expresa, a partir del hecho de que el joven vulnerable al transformarse en trabajador obtiene una retribución económica muy baja en comparación con otros jóvenes chilenos de clases medias y altas. Estas consecuencias de la inequidad que enfrenta el joven vulnerable, lo identificará como un joven trabajador pobre, teniendo como consecuencia la posible deserción del mercado del trabajo y, por lo tanto, dejar de ser un joven productivo. Ahora bien, en esta oscilación entre inequidad y la posible amenaza de que el joven deje de ser productivo, emerge el discurso de la delincuencia. Esta asociación de la juventud vulnerable al margen de la legalidad, se puede ejemplificar con afirmaciones tales como: 'Estas dificultades generan los incentivos para la búsqueda de otras fuentes de ingresos, tanto en el sector informal o en otras actividades que pueden llevar al joven incluso a la delincuencia, con las graves consecuencias personales, familiares y sociales que esto acarrea'.

En esta línea, a lo largo del fragmento, se puede visualizar la forma en que la carencia es presentada desde una forma específica, en este caso está asociada a la familia, hecho que favorece la individualización del problema. En ningún momento se hace referencia a la carencia como un fenómeno estructural de carácter macro social, asociado a un sistema económico ó relacionada a una clase social específica.

Como veremos a continuación, las políticas de empleo juvenil centradas en esta nueva Ley elaboran y prescriben una propuesta desde la formalidad del trabajo, para lo cual es necesario que el joven sea capacitado en programas orientados a la empleabilidad juvenil, que faciliten la inclusión del joven carente a los mercados del trabajo como parte de su disciplinamiento. A continuación, presentaremos una cita de cómo se argumenta esta propuesta.

\section{Categoría 3: La formalización del trabajo}

\section{Cita $N^{\circ} 3$}

\section{'La importancia de un trabajo formal' (Subtítulo)}

La transición de los jóvenes a un empleo formal y de calidad luego de finalizar sus estudios, ya sea de enseñanza media o educación superior, es uno de los ejes centrales para el buen funcionamiento del mercado del trabajo y del sistema educacional. Fomentar el empleo formal de calidad ha sido una prioridad para mi Gobierno. Un empleo de estas características le permite al joven insertarse en la sociedad de manera productiva, procurarse de una remuneración y, en consecuencia, acceder a una mejor calidad de vida. Un empleo formal y estable es uno de los logros más valorados después de años de esfuerzo de los jóvenes y sus familias tras el término de los estudios. Esta retribución al esfuerzo actúa como catalizador para seguir esforzándose en aumentar sus niveles de bienestar, al tiempo que sirve de ejemplo positivo para su entorno más cercano. El empleo formal es también un canal de acceso efectivo a las instituciones del sistema de protección social, como el seguro 
de salud, el seguro contra accidentes del trabajo y enfermedades profesionales, el seguro de cesantía y el ahorro para la vejez. Asimismo, le permite al joven seguir aumentando su capital humano con experiencia laboral y capacitación, ya sea en competencias laborales o en competencias generales. Aumentar el capital humano es esencial para que el joven pueda seguir desarrollando sus competencias y así poder acceder a mejores trabajos formales que lo llevarán a un mejor nivel de vida. Una persona que tiene un empleo formal tiene más posibilidades de continuar en un empleo de estas características creando de esa forma un círculo virtuoso donde la formalidad lleva a más formalidad y por lo tanto el joven se arraiga con más fuerza y sustentabilidad en el mundo productivo. Finalmente, esta modalidad de empleo promueve que el joven fortalezca sus lazos de pertenencia con la sociedad y disponga de los recursos y tenga acceso a la protección social necesaria para desarrollar su vida con más y mejores oportunidades.

(Mensaje de la Presidenta para iniciar proyecto de ley que crea el subsidio al empleo. Congreso Nacional, 2009: 4).

Esta tercera cita es tomada de un discurso de la presidenta Bachelet, en el marco de la proclamación de Ley de Subsidio al empleo juvenil (2009). A partir de este fragmento, se puede ilustrar la importancia de la formalidad del trabajo para la juventud como elemento fundamental para los lineamientos de la 'política social y laboral para el nuevo siglo'.

A partir del texto, se puede constatar que la juventud es entendida por las políticas de empleo como un proceso de transitoriedad en el ciclo de vida, donde el joven tiene que cumplir con una serie de criterios normativos para ser categorizado como adulto. Desde esta perspectiva, el joven que accede a educación formal tiene el 'deber' de transformase en un sujeto productivo y empleable para la sociedad. Esto último coincide con las políticas desarrolladas por el Instituto nacional de la Juventud (2013), han denominado 'inserción laboral funcional'14.

La propia presidenta se plantea como hablante en primera persona cuando hace referencia a 'Fomentar el empleo formal de calidad ha sido una prioridad para mi Gobierno'. En esta línea, el empleo estable y formal se plantea como uno de los mayores logros sociales que el joven puede acceder, después del tiempo invertido tanto del propio joven, como de sus familias y del Estado en materia educativa. La formalidad del trabajo planteada como una retribución social hacia el joven y su familia, permitirá al joven seguir esforzándose para un mayor bienestar. Además, este joven que logra su inclusión social desde un trabajo estable, es un ejemplo para su entorno más cercano, principalmente por su esfuerzo y el de su familia. La formalidad del trabajo permite la inclusión del joven a la sociedad y, por lo tanto, acceder a una serie de beneficios sociales como por ejemplo la protección social basada en una serie de seguros y en la pensión para la vejez.

En la cita presentada es posible ilustrar como está presente la inversión en el sujeto niño-adolescente-joven desde la perspectiva del capital humano. A partir de esto, la nueva política ofrece 'un empleo formal y estable' y de calidad, como retribución a todo este esfuerzo y la inversión realizada desde distintos actores que son parte de la red más cercana

\footnotetext{
${ }^{14}$ En la séptima encuesta nacional de Juventud (2013), esta forma 'funcional' de entender la inserción social permite ilustrar como se interpela al joven a ser parte de la sociedad como un sujeto productivo, basado en el discurso de la formalidad del trabajo.
} 
de este sujeto joven. Entonces, desde este primer hito de inclusión social que culmina con un trabajo formal, el joven debe continuar desarrollando su capital humano a lo largo de su vida, hecho que le permitirá acceder a mejores trabajos. El empleo formal se plantea como una plataforma para que el joven siga accediendo a más capital humano, a partir de ahora, ya no desde su capacitación para acceder a un empleo, sino desde el ámbito de su experiencia laboral. Esto permitirá mayor remuneración y mejor calidad de vida, por lo tanto, el joven se establece con 'más fuerza y sustentabilidad en el mundo productivo'. De esta manera el joven que accede al mundo del trabajo desde los lineamientos de la mejor política social y laboral, será incluido socialmente desde el argumento que 'la formalidad lleva a más formalidad', posicionando de esta manera al joven en el mundo productivo.

A continuación, veremos cómo estas políticas se materializan en un nivel de programático. La siguiente cita es parte de un manual del programa Más Capaz que está dirigido a los profesionales y técnicos que trabaja con los jóvenes vulnerables.

\section{Categoría 4: El joven analfabeto del Management.}

\section{Cita $N^{\circ} 4$}

Los(as) Jóvenes (Subtítulo)

Muchos jóvenes carecen hoy de las habilidades fundamentales requeridas en el mundo laboral actual, que los conviertan en candidatos atractivos a diversos puestos de trabajo. Estos no cuentan con las habilidades técnicas, ni otras habilidades caracterizadas como "habilidades blandas, transversales o para la vida", como por ejemplo: la comunicación asertiva, la confiabilidad y la capacidad para trabajar en equipo, por mencionar algunas. Todas ellas, habilidades que articuladas a los conocimientos, son necesarias en cualquier tipo de trabajo.

(Servicio Nacional de Capacitación y empleo. Guías operativas. Programa Más Capaz 2015: 5-6)

En el fragmento seleccionado, se puede ilustrar que la descripción del joven vulnerable es de un individuo extremadamente carenciado de recursos para enfrentar el mundo productivo. Esto por una total ausencia de 'habilidades fundamentales requeridas en el mundo laboral actual', que no los hace 'candidatos atractivos' para acceder a puestos de trabajo. Es más, el joven vulnerable se conceptualiza como un sujeto que carece de 'habilidades para la vida'. Es decir, es un sujeto que de acuerdo a la definición de la política, no podrá sobrevivir en los mercados del trabajo. A partir de lo anterior, podemos entender que el usuario de los programas de empleo corresponde a un joven totalmente analfabeto del discurso managerial (Parker, 2002). Por lo tanto, el joven vulnerable debe incorporar el discurso dominante del mercado y del Management como un nuevo idioma que es mandatado a entender, este nuevo lenguaje es su puerta de entrada para su inclusión social, ya que es la única forma posible que tendrá para buscar empleo y poder ser contratado por algún empleador y por lo tanto acceder a la formalidad del trabajo.

La definición de 'Los(as) Jóvenes' del programa Más Capaz, permite ilustrar como los programas de empleo se encargan de alfabetizar en Management al joven vulnerable, ya que éste tiene el 'deber' de incorporar el lenguaje empresarial y desarrollar una serie de habilidades que le permitan no sólo hablarlo, sino también actuarlo o, en términos performativos, incorporarlos desde el desarrollo de habilidades como la 'comunicación 
asertiva', la 'confiabilidad', y desarrollar la 'capacidad para trabajar en equipo'. La adquisición de este nuevo lenguaje (verbal y performativo) corresponde a una asimilación normativa que le permitirá al joven el 'disciplinamiento necesario' (Cita 2) para su inserción laboral.

\section{Eje 2.- De la ideología al sujeto: Neoliberalismo y la producción del joven trabajador chileno}

Los cuatro fragmentos presentados permiten entender que los discursos que construyen al joven trabajador en Chile corresponden a un gran entramado de distintos hilos discursivos (Fairclough, 2010) que están presentes en las políticas de empleo juvenil. A continuación, desde una perspectiva de los Estudios de la Gubernamentalidad, profundizaremos en cómo las políticas generan una serie de discursos que permiten 'conducir la conducta' de los jóvenes vulnerables, hacia su inserción a los mercados del trabajo.

\section{Las políticas Neoliberales centradas en la autoestima}

En los resultados presentados, se ha podido apreciar cómo el discurso neoliberal se empieza a aplicar a las políticas de empleo juvenil, modelando y prescribiendo al joven vulnerable como un sujeto productivo. Siguiendo a Miller y Rose (2009), las economías avanzadas que han implementado una ideología neoliberal en sus políticas, han definido una nueva forma de entender al sujeto de gobierno. Se plantean desde una racionalidad donde el individuo es autónomo y debe realizarse a sí mismo como un 'sujeto autogobernable' (Pulido y Sato, 2013; Pulido-Martínez, 2008; Sisto, 2012; Vera, 2013). En el contexto chileno vemos como este proceso ocurre con la instalación de 'la políticas social y laboral para un nuevo siglo' (CAPTE, 2008), donde se explicita una nueva forma de entender la problemática del empleo-desempleo, basada en el argumento centrado en que "cada persona tenga empleo, y éste proporcione un ingreso que permita cubrir un nivel de vida satisfactorio" (cita $\mathrm{N}^{\circ} 1$ ). De acuerdo a Rose (1997) esto obedece a nuevas formas de entender 'lo social', ya que, a diferencia de las prácticas del Estado de bienestar, este nuevo régimen que se caracteriza por una apertura al mercado, supone un yo activamente responsable. Así, el nuevo énfasis esta puesto en las responsabilidades individuales de los sujetos, familias y comunidades respecto de su propio bienestar.

La política neoliberal promueve un 'ciudadanía activa' (Dean, 1995), que debe tener una autoestima necesaria para insertarse a los mercados del trabajo. En esta línea, la 'autoestima' corresponde a un elemento que emerge trasversalmente en el corpus seleccionado. Tal como fue mencionado más arriba, las políticas centradas en la autoestima, obedecen a una perspectiva centrada en el ‘autogobierno' (Cruikshank, 1993), la cual busca disminuir los sujetos problemáticos carenciados y asistidos. Afirmaciones tales como "poniendo los acentos en la autoestima y la autosustentación" (cita $\mathrm{N}^{\circ} 1$ ) o cuando se hace referencia al "desaliento" en torno a la participación laboral de los jóvenes (cita $\mathrm{N}^{\circ} 2$ ), o afirmaciones que plantean a un joven que no tiene "habilidades para la vida" (cita $\mathrm{N}^{\circ} 4$ ), dan cuenta de cómo la perspectiva del autogobierno se instala como tecnología de gobierno en las políticas de empleo juvenil en el Chile actual.

Esta perspectiva del autogobierno se materializa desde una racionalidad y un saber que tiene como base el discurso del Management. Este saber managerial, coloniza los discursos y prácticas propias de una política asistencial, la cual tiene que ser dejada atrás 
con el siglo XX y ser sustituida por un nuevo lenguaje, centrado en un sujeto productivo basado en el 'Nuevo enfoque para la equidad'. Tal como se ha ilustrado en los resultados, estas políticas plantean una inserción de una ciudadanía activa en los mercados del trabajo desde un empleo formal.

\section{La 'obsesión' por la formalidad del trabajo}

Siguiendo las conceptualizaciones presentadas en el marco conceptual, el 'Individuo empleable' es una categoría normativa en los discursos del trabajo. Esta obedece a formas idealizadas de sujetos competentes que son definidas por las políticas públicas (Garsten y Jacobsson, 2013; Rentería y Malvezzi, 2008). A lo largo de las citas presentadas, emerge la importancia del empleo formal, el cual obedece a una forma dominante de entender el trabajo en las nuevas políticas laborales desarrolladas a partir del año 2008.

En los resultados dimos cuenta de que existe una especie de 'obsesión' en los lineamientos de la 'mejor política' en relación a las nuevas formas de entender el empleodesempleo desde la formalidad. Esto se puede ejemplificar en afirmaciones tales como "un empleo formal y de calidad luego de finalizar sus estudios, ya sea de enseñanza media o educación superior, es uno de los ejes centrales para el buen funcionamiento del mercado del trabajo y del sistema educacional" (cita $\mathrm{N}^{\circ} 3$ ). Ahora bien, la pregunta que surge al respecto es si efectivamente es posible eliminar el trabajo y la economía informal en el contexto chileno. Probablemente eso no sea posible, sin embargo, como se ilustró en la cita $\mathrm{N}^{\circ}$ 3, la informalidad está asociada a la pobreza y a las familias de origen de los jóvenes vulnerables, así como al discurso de seguridad pública centrado en la delincuencia.

Vemos que el nuevo discurso centrado en la formalidad se plantea desde una lógica de 'retribución' para los jóvenes que culminan sus estudios. Esta idea de retribución, permite entender como emerge el discurso basado en las teorías del capital humano como forma argumentativa para formalizar el trabajo de la juventud vulnerable. En esta línea, y siguiendo a Bowles y Gintis (1975), la escolarización y la capacitación son la base de una mano de obra disciplinada. El requisito que plantea la política es que el joven que es usuario de los programas de empleo está obligado a capacitarse, es decir tiene el deber de generar una serie de competencias en habilidades técnicas y blandas que le permitan desarrollar los "hábitos y de la disciplina necesaria para mantener y progresar en un trabajo subordinado" (cita $\mathrm{N}^{\circ} 2$ ).

Esto último, espera generar como consecuencia una serie de procesos identitarios y de pertenencia social. El joven productivo que accede al empleo formal será parte de un gran 'nosotros' que valorará su forma de ser incluido a la sociedad, ya que tendrá a su disposición una serie de recursos y la protección necesaria para mayores oportunidades en la vida, distanciándose y dejando atrás la figura del joven vulnerable.

\section{IV.- REFLEXIONES FINALES}

El presente artículo se ha preguntado cómo las políticas de empleo en Chile construyen al joven trabajador en el proceso de neoliberalización de las políticas del trabajo, desarrolladas durante las últimas décadas. A partir de la revisión de documentos públicos, se ha podido constatar una serie de discursos que emergen desde las políticas y que conforman un engranaje que nos permite entender cómo se construye al joven trabajador chileno. 
A partir del análisis presentado, se puede ilustrar cómo las propuestas Neoliberales del 'Nuevo enfoque para la equidad' se van imbricando con un lenguaje jurídico que va conformando nuevas políticas, leyes y programas que justifican la 'regulación social del empleo juvenil en Chile'.

A lo largo de este artículo, hemos podido dar cuenta que partir del año 2008 con los lineamientos del Consejo Asesor Presidencial, los nuevos discursos de las políticas de empleo se consolidan y hacen visible una nueva comprensión del joven trabajador. Las formas de interpelación normativa al joven vulnerable corresponden a una serie de hilos discursivos que se van consolidando en el tiempo y conforman una serie de trazas que hacen visible una nueva forma de entender al joven trabajador chileno de nuestros días.

El hecho de centrarse en los discursos de las políticas de empleo juvenil, permite dar luces de cómo opera la ideología y qué tipo de sujetos produce. Siguiendo a Fairclough (2010), reproduce relaciones de poder desiguales entre clases sociales, de acuerdo a cómo se sitúa a los sujetos. En esta línea, la lógica de autogobierno centrada en la autoestima permite identificar tecnologías de control y una serie de prescripciones normativas dirigidas a jóvenes vulnerables argumentadas desde el Management.

Finalmente, en base a los resultados y al análisis propuesto se invita a generar una reflexión mayor en torno a cómo las políticas laborales, no sólo buscan generar un nuevo joven trabajador, sino un 'nuevo ciudadano'. A partir de esta idea, para futuros estudios se sugiere conectar las políticas laborales centradas en la juventud vulnerable con políticas de salud, educativas y de participación, entre otras. Esto desde la inquietud por conocer la forma como se construye y gobierna no sólo al joven trabajador, sino a la 'juventud vulnerable' como sujeto social del Chile actual.

LEICESTER (REINO UNIDO), DICIEMBRE 2015

RECIBIDO: MARZO, 2016

ACEPTADO: JULIO, 2016

\section{V.- REFERENCIAS BIBLIOGRÁFICAS}

AGUILERA, O. (2009). "Estudios sobre juventud en Chile: Coordenadas para un estado del Arte". Última Década Vol. 31. Valparaíso: CIDPA.

ALVESSON, M. (2008). "The future of Critical Management Studies”. En Barry y Hansen (2008). The SAGE Handbook of New Approaches in Management and Organization. London: Sage.

ASSUSA, G. Y BRANDÁN, M.G. (2014). "Salvar la generación perdida: Gubernamentalidad, empleabilidad y cultura del trabajo. El caso de un programa de empleo para jóvenes en Argentina". Revista Sociología e Política, Vol. 22.

ATKINSON, P. Y COFFEY, A. (2006). "Analysing documentary realities". En Silverman, D. (Ed.) Interpreting Qualitative Data. London: Sage.

BACHELET, M. (2013). 50 Compromisos para los primeros 100 días de Gobierno.

BECKER, G. (1993) Human capital: a theoretical and empirical analysis, with special reference to education. London: University of Chicago Press. 
BRANDÁN, M.G. (2014). “Juventud, trabajo y dispositivos estatales. Aportes críticos a la sociología de la juventud desde la perspectiva de la Gubernamentalidad". Última década, Vol. $40 \mathrm{~N}^{\circ} 1$. Valparaíso: CIDPA.

BOWLES, S. Y GINTIS, H. (2014/1975). "El problema de la Teoría del Capital Humano: Una crítica Marxista". Revista de Economía Crítica, Vol. 18 N² 2.

BUCHEL, G., GORDON, C., MILLER, P. (1991). The Foucault effect: Studies in Governmentality. Chicago: The University of Chicago press.

CASTRO-GÓMEZ, S. (2010). Historia de la Gubernamentalidad. Razón de Estado, liberalismo y neoliberalismo en Michel Foucault. Bogotá: Siglo del Hombre Editores.

CHERTKOVSKAYA, E., WATT, P., TRAMER, S., SPOELSTRA, S. (2013). "Giving notice to employability". Ephemera, Vol. 13 N4.

CONGRESO NACIONAL (2009). Historia de la Ley $N^{o}$ 20.338. Crea el Subsidio al empleo. Santiago.

---- ---- (2009). Mensaje de S.E la Presidenta de la República con que inicia un proyecto de ley que crea el subsidio al empleo.

---- ---- (2009). Cámara de Diputados. Discusión en sala Subsidio al empleo juvenil. Primer trámite constitucional. Legislatura 357, Sesión 02. Fecha 12 de marzo, 2009.

---- ---- (2009). Senado de la República. Informe de la comisión de Hacienda recaído en el proyecto de ley en segundo trámite constitucional, que crea el subsidio al empleo. 18 de marzo, 2009

---- ---- (2009). Senado de la República. Discusión en sala Subsidio al empleo juvenil. Legislatura 357, Sesión 04. Fecha 18 de marzo, 2009.

---- ---- (2009). Oficio de Ley a S.E. la Presidenta de la República, comunica texto aprobado por el Congreso Nacional. Fecha 19 de marzo, 2009.

--- ---- (2009). Firma proyecto de Ley Subsidio al empleo. Intervención de S.E la Presidenta de la República Michelle Bachelet, en acto de firma del proyecto de ley sobre subsidio al empleo.

CONSEJO ASESOR PRESIDENCIAL: TRABAJO Y EQUIDAD (2008). Hacia un Chile más justo: Trabajo, salario, competitividad y equidad social. Santiago.

CRUIKSHANK, B. (1993). "Revolution whitin the self: Self-government and self-esteem". Economy and Society, Vol. 22 №3.

DEAN, M. (2007). Governing societies. London: Open University Press. Mc Graw-Hill Education.

--- --- (1995). “Governing the unemployed self in an active society”. Economy and Society, Vol. $24 \mathrm{~N}^{\circ} 4$.

DIEDRICH, A. Y STYHRE, A. (2013). "Constructing the employable immigrant: The uses of validation practices in Sweden". Ephemera, Vol. 13 No4.

DU GAY, P. (1996). Consumption and identity at work. Londres: Sage.

ESPINOZA Y RIVERA (2015). Estudios Críticos de la Administración en Chile. Disponible en http://www.criticalmanagement.org/node/3206

FAIRCLOUGH, N. (2010). Critical Discourse Analysis. The critical study of language .London: Longman.

FAIRCLOUGH, N. Y WODAK, R. (2000). “Análisis crítico del discurso”. En T. Van Dijk (Ed.), El discurso como interacción social. Barcelona: Gedisa.

FEJES, A. (2010). "Discourses on employability: Constituting the responsible citizen". Studies in continuing education, Vol. 32 No2. 
FERNÁNDEZ-RODRÍGUEZ, C. (2012). “Estudio Preliminar. La obra de Paul du Gay como una vía alternativa en los estudios críticos de la organización”. En Du Gay, En elogio de la burocracia. Madrid: Siglo XX.

FLEW, T. (2014). "Six theories of neoliberalism". Thesis Eleven, Vol. 122 Nº1.

FOUCAULT, M. (2009). Seguridad, territorio y población. Argentina: Fondo de cultura económica.

--- ---- (2012). Nacimiento de la Biopolítica. Argentina: Fondo de cultura económica.

---- ---- (2012b). Tecnologías del Yo y otros textos a fines. España: Paidós.

GARSTEN, C. Y JACOBSSON, K. (2013). "Sorting people in and out: The plasticity of the categories of employability, work capacity and disability as technologies of government". Ephemera, Vol. 13 №4.

GAZIER, B. (2001). "Employability: The complexity of a policy notion". En Weinert, P.; Baukens, M.; Bollerot, P.; Pineschi-Gapanne, Walwei, U. Ed. Employability: From theory to practice. London: Transaction Publishers.

GOBIERNO DE CHILE (2015). Mensaje Presidencial. 21 de Mayo de 2015.

---- ---- (2014). Mensaje Presidencial. 21 de Mayo de 2014.

GRINBERG, S. (2007). "Gubernamentalidad: estudios y perspectivas". Revista Argentina de Sociología. Vol. 5 (8).

HANLON, G. (2016). The dark side of management. A secret history of management theory. London: Routledge.

HOLMQVIST, M., MARAVELIAS, C, SKALEN, P. (2012). "Identity regulation in neo-liberal societies: Constructing the "occupationally disabled" individual". Organization, Vol. 20 No2.

IBÁÑEZ, S. (2005). El trabajo visto por los jóvenes chilenos: un análisis de las representaciones sociales de los jóvenes urbano populares. Montevideo: OIT/Cinterfor.

INJUV (2013). Séptima Encuesta Nacional de Juventud 2012. Santiago: Maval Ltda.

JAGER, S. (2003). "Discurso y conocimiento: Aspectos teóricos y metodológicos de la crítica del discurso y del análisis de dispositivos”. En Wodak, R. y Meyer, M. (Comp.). Métodos de análisis crítico del discurso. Barcelona: Gedisa.

KAASCH, A. (2013). "Contesting contestation: Global social policy prescriptions on pension and health systems". Global Social Policy, Vol. $13 \mathrm{~N}^{\mathrm{o}} 1$.

KURUNMÃKI, L., LAPSLEY, L., Y MILLER, P. (2011). "Accounting within and beyond the state". Management Accounting Research, Vol. $1 \mathrm{~N}^{\mathrm{o}} 22$.

MILLER, P. Y ROSE, N. (2009). Governing the present. Reino Unido: Polity Press.

PARKER, I. (1996). "Discurso, cultura y poder en la vida cotidiana”. En Gordo, A. y Linaza, J. (Comp.) (1996). Psicologías, Discursos y Poder (PDP). Madrid: Visor.

PARKER, M; CHENEY, G; FOURNIER, V.; LAND, C. (2014). The Routledge Companion to Alternative Organization. London: Routledge.

PARKER, M. (2002). Against Management. Reino Unido: Polity Press.

PRIOR, L. (2006). "Doing things with documents". In Silverman, D. (Ed.) Interpreting Qualitative Data. Sage: London.

PULIDO-MARTÍNEZ, H. C. (2012). "El trabajador libre y la psicología del trabajo". En S. Trujillo-García y H. C. Pulido-Martínez (Eds.), Libertad y psicología. Tensiones y debates desde Iberoamérica. Bogotá: Editorial Pontificia Universidad Javeriana.

--- ---- (2008). "Produciendo trabajadores modernos. Conocimiento psicológico y el mundo del trabajo en el sur". Universitas Psychologica, Vol. 6 Nº 1.

--- ---- Y SATO, L. (2013). “...Y entonces ¿esto de la crítica qué es? De las relaciones entre la psicología y el mundo del trabajo". Universitas Psychologica, Vol. 12 No4. 
RENTERIA, E. Y MALVEZZI, S. (2008). “Empleabilidad, cambios y exigencias psicosociales en el trabajo". Universitas Psychologica, Vol. 7 No2.

RIVERA, G. (2015). "La construcción discursiva del joven trabajador: Un análisis crítico a los informes tendencias mundiales de empleo". (Artículo en revisión).

RODRÍGUEZ, M. (2000). "Reflexión sobre la experiencia de política de juventud en Chile". Última Década Vol. 12. Valparaíso: CIDPA.

ROSE, N. (1997). "El gobierno de las democracias liberales "avanzadas": del liberalismo al neoliberalismo". Revista Archipiélago, Vol. 29.

---- ----. (1996). Inventing our selves. Psychology, power and personhood. Reino Unido: Cambridge University Press.

---- ---, O' MALLEY, P., VALVERDE, M. (2012). “Gubernamentalidad”. Astrolabio, Vol. 8.

SAÉNZ, J. Y GRANADA, C. (2013). El dispositivo de lo social como gobierno de los pobres en la primera mitad del siglo XX en Colombia. Proyecto ensamblando Colombia. Tomo 1. Universidad Nacional de Colombia: Bogotá.

SENELLART, M. (2009). “Situación de los cursos”. En Seguridad, territorio y población. Argentina: Fondo de cultura económica.

SERVICIO NACIONAL DE CAPACITACIÓN Y EMPLEO SENCE. (2015). Guías operativas 2015. Programa Más Capaz.

SCHULTZ, T. (1971). Invest in Human capital: The Role of Education and of Research, New York: Free Press

SISTO, V. (2012). "Identidades desafiadas: individualización, managerialismo y trabajo docente en el Chile actual". Psykhe, Vol. $21 \mathrm{~N}^{\circ} 2$.

SISTO, V. Y FARDELLA, C. (2011). "Nuevas políticas públicas, epocalismo e identidad: el caso de las políticas orientadas a los docentes en Chile". Revista de Estudios Universitarios, Vol. $37 \mathrm{~N}^{\circ} 1$.

STECHER, A. (2010). "El análisis crítico del discurso como herramienta de investigación psicosocial del mundo del trabajo. Discusiones desde América Latina”. Universitas Psychologica, Vol. $9 \mathrm{~N}^{\mathrm{o}} 1$.

--- ---- (2014). "Fairclough y el lenguaje en el Nuevo Capitalismo: Análisis de las dimensiones discursivas del mundo del trabajo". Psicoperspectivas, Vol.13 No3.

---- ---- Y GODOY, L. (2014). Transformaciones del trabajo, subjetividad e identidades. Lecturas psicosociales desde Chile y América Latina. Ril Editores: Santiago de Chile.

VARGAS-MONROY, L. Y PUJAL, M. (2013). Gubernamentalidad, dispositivos de género, raza y trabajo: la conducción de la conducta de las mujeres trabajadoras. Universitas Psychologica, Vol. $12 \mathrm{~N}^{\circ} 4$.

VERA, A. (2013). “Creatividad empresarial y autogobierno: un análisis discursivo”.Universitas Psychologica, Vol. 12 No4.

VESTERBERG, V. (2013). "Ethnicized un/employability: Problematized others and the shaping of advanced liberal subjects". Ephemera, Vol. 13 No2. 